Open Access

\title{
Arts catalyst of creative organisations for the fourth industrial revolution
}

\author{
Giovanni Schiuma
}

Correspondence:

giovanni.schiuma@unibas.it Department of Mathematics, Informatics and Economics, University of Basilicata, Viale dell'Ateneo Lucano, Potenza, Italy

\begin{abstract}
Today's digital era challenges organisations not only to follow the technological trajectories, by developing new technological solutions and/or adopting the latest disruptive technology, but most importantly to become creative and resilient organic systems that are open to changes and keen to experiment and innovate continuously. For this reason, organisations need to shape a creative environment in which technology and creativity are fully integrated and intertwined. This can be achieved by integrating the emotional and aesthetic aspects of an organisation with the technical and rational dimensions distinguishing the technology.

This paper argues that, in the context of the so labelled fourth industrial revolution, successful organisations are those that exert innovative capability by becoming techno-human systems developing and melting emotional and rational knowledge. In accordance with this view, managers alongside the deployment of innovative technologies - which defines the techno-based dimensions of an organisation they have to nurture an organisational creative environment which reflects and empowers the human-based characteristics. This can be achieved by taking into account the aesthetic dimensions and properties of an organisation and by bringing artistic projects and/or attitudes into the organisation in order to trigger critical and creative thinking. The instrumental use of the arts as a management innovation for the creation of an organisational context which nurtures human potential and creative thinking is illustrated through the analysis of some of the key arts based initiatives put in place by Elica, an Italian world leader company in the design and production of kitchen hoods.
\end{abstract}

\section{Introduction}

Different interchangeable labels have been coined and used to describe the innovations of today's new socioeconomic era, such as Digital Age, the Fourth Industrial Revolution, the Internet of Things/Everything, or the Industrial Internet. In particular, in the last years, the notion of the Fourth Industrial Revolution has been proposed by the World Economic Forum to sign the drastic and accelerated development of technologies and their impact on society at large. It is argued that the development of digital and intelligent technologies in conjunction with biology and their combination and application to the physical world defines a new industrial revolution. New technology-enabled platforms capable of combining both demand and supply are already disrupting existing industries and shaping new business landscapes such as the "sharing" or "on demand" economy (Schwab, 2016). Two main drivers of this revolution can be recognised, on the one hand,

(c) The Author(s). 2017 Open Access This article is distributed under the terms of the Creative Commons Attribution 4.0 International License (http://creativecommons.org/licenses/by/4.0/), which permits unrestricted use, distribution, and reproduction in any medium, provided you give appropriate credit to the original author(s) and the source, provide a link to the Creative Commons license, and indicate if changes were made. 
the development of industries from the pre- to the post- Fordism era, and on the other hand, the development of internet and the connected 'digital world', i.e. all applications and infrastructures related to the Web. To denote the implications of these two paths of innovation on the transformation of global industry and daily life, General Electric uses the notion of Industrial Internet, i.e. the combination of the physical world and internet (Evans and Annunziata, 2012). The manifestations of this combination defines the technology landscape which includes a number of key dimensions ever evolving, such as: Connectivity; Big Data; Automatization; Intelligent Agents, Robotics; Machine Learning; Artificial Intelligence; Blokchain; Sensors; Virtuality; 3D printing; and Augmented reality. These technologies and their convergence, integration and development have the digital dimension as common denominator and overall represent the key technological pillars characterising today's Digital Age.

Independently from the adopted ontology and terminology the Digital Age, or Fourth Industrial Revolution represents a shift of paradigm with a new wave of innovations characterized by the digitization of business, society and our lives. These innovations will increasingly transform how organisations and institutions do their businesses, operate their productions, and impact on society and make their ecological footprint as well as how people live their lives. These innovations entail the development, deployment and exploitation of technologies, but their initiation and growth are strongly affected by the creative characteristics of organisations. Indeed, at the centre of the creation and growth of any technological solution there is always the aspirations, curiosity, creativity, competence and passion of people who have imagined, prototyped and tested a technology. Therefore, the understanding of what drives the Digital Age has to take into account the human-based dimensions and characteristics as much as the technological ones, and in addition has to consider the biological components that define the ecology of life. This means that the Fourth Industrial Revolution is primarily concerned about the integration of Technology, Humanity and Biology. This, in other words, means that the key characteristic of the Digital Age is the shaping of Techno-Human Intelligent Systems, i.e. systems that integrate technological and human characteristics and are organic and living in nature, so that they are capable of dynamically learning and evolving in relation both to the context in which they operate and to the problems/challenges they have to face. This view of the Techno-Human Intelligent Systems acknowledges the centrality of people as much as of the technology. As evocatively formulated by General Electric, the new wave of innovations is about "machine + minds", i.e. the relationships between technologies and people to support intellectual activities that can exploit the computational capacity of machines.

The successful organisations of the Digital Age will be those recognising that as much as they will become more technologically advanced, the people will still be at the heart of organisational life and actually the most human distinguishing factors will become even more fundamental for the creation and deliver of value. Indeed, the organisations' innovation dynamics and value creation mechanisms are affected by the logical and rational components as well as by the emotional and creative dimensions, e.g. empathy, intrinsic motivation, curiosity and imagination. The engagement of these emotional and creative aspects is what distinguish people's contribution from technologies and, ultimately, it what an organisation turns into technological solutions, products and services that embed value for society. 
The success of digital companies such as, for example, Google cannot be explained without taking in account the deep human nature of these organisations that are continuously able to generate disruptive innovations by sustaining themselves as creative organisations. Google has created a capacity for change and innovation by shaping organisational contexts in which creativity could flourish. Employees are given time and space to cultivate and express their creativity so that they can be encouraged to continuously search for new solutions to emergent and potential business problems. Great attention has been paid to the aesthetic properties of the workplace so that it can inspire and energise employees' creativity. The workplace is enriched with playground areas (equipped with bar football and table tennis tables), and services for employees including free meals during the day, coffee corners, gym, spa, meditation and resting areas, and rooms where people can play music. All these solutions are aimed at managing the organisational aesthetic dimensions and properties in a way that human senses can be stimulated creating positive employees' experiences which in turn may certainly influence their emotive states and drive the enhancement of the existing technological platform as well as the prototype and development of new solutions.

The aim of this paper is to explore how in today's Digital Age organisations can shape and nurture a creative environment in which change is a 'state of mind' and employees have the capability to be imaginative and engaged to embrace transformation, continuously accepting and searching for new valuable solutions. The Fourth Industrial revolutions calls for organisations to be not only technologically advanced but very importantly able to develop a capacity to respond creatively to discontinuous changes and accordingly to be more and more flexible, agile, intuitive, imaginative and resilient. Shaping a creative environment organisations enable people to discover and express their potential so that by using their full cognitive capabilities they can find novel valuable solutions to problems and challenges. The development of a creative environment is based on the idea that an organisational system is a living organism whose capacity for being intuitive, imaginative, resilient, creative and adaptable, is based on its human-based nature (Hamel, 2000, 2007, 2009; Schiuma, 2011). In fact, the ability of an organisation to be intuitive and imaginative is tied to the employees' willingness and ability to exercise their creativity and imagination in daily work activities as well as the flexibility and resilience of an organisation is strongly affected by the employees' capacity to tackle stress, anxiety or fear of failure.

The focus of this paper is on the investigation of how organisations can shape creative environments by adopting the arts as a catalyst for creativity and innovation. Acknowledging the techno-human nature of the organisations in the digital age, it is argued that the arts can be deployed as a managerial means to shape organisations' creative environments. Insights about how to deploy the arts as a driver for shaping creative organisations are gathered from the analysis of the case example of Elica: an Italian company world leader in the design and production of kitchen hoods. Despite technological nature of Elica's products and services, the company is continuously developing an organisational creative environment capable of sparking, fostering and developing human potential and creative thinking by using the arts as a catalyst.

\section{Distinguishing the human-based nature of organisations in the digital age}

In the new Digital Age, organisational success will not solely depend upon the ability to adopt, develop and exploit technologies. Successful organisations need to distinguish 
the human-based nature of their organisational life and components (Adler, 2010). Indeed, in the Fourth Industrial Revolution, organisations will be increasingly challenged to develop a capacity for change and innovation. The pace of change and the disruptive nature of innovations will require that organisations become more and more agile, intuitive, imaginative, and open to change. This can be achieved only by developing the human-based dimensions of an organisation. Therefore, the Fourth Industrial Revolution it is not only about embracing new disruptive digital-based technologies and learning machines, but it is also about shaping organisational environments that let people express their real potentials and be in touch with their positive emotions.

In the Digital Age it will be fundamental to take into account that organisations' functions and existence is characterised and based on vital phenomena. These include, at the same time, the technological dimensions and the emotive and inner dimensions of human-based characteristics. These two dimensions are inseparable unless an organisation is made into a 'machine-like system', removing the human presence. This means that technology and humanity have to be seen as two intertwined pillars of development and continuously put in conversation.

In order, to acknowledge and point out the dual and inseparable twofold technological and human-based nature of organisations in the digital age, the view of the organisation as a techno-human system is introduced. This view considers organisations as living organisms (Burns and Stolker, 1961) and stresses that organisational behaviours are strongly affected by aesthetics and emotions in organisations (Fineman, 1985; Frost et al., 1985; Linstead and Höpfl, 2000; Mintzberg, 1985; Strati, 1992; 2000a; Turner, 1990). Accordingly, the technological and rational-based knowledge assets as well as the organisational aesthetic and emotive features have to be managed by organisations in order to sustain success and achieve excellence (Strati, 1992, 2000a; Taylor and Hansen, 2005). Indeed, emotions play a central role in explaining the quality of the organisational value creation capacity. They act as enablers and/or barriers towards business models and processes innovation, having the capacity to moralise and demoralise, mobilise and immobilise organisational energies (Frank, 1988). In particular, emotions affect the engagement of people to give the best of themselves as well as to exercise their curiosity and creativity in order to see new possible and valuable solutions. According to Dick Richards (1995) "engagement occurs when [people] experience a deep sense of caring about the work, a sense that what [they] are doing is worthwhile in and for itself." (p. 31). The creation of this 'sense of caring' requires that organisations address people's emotions (Richards, 1995). They affect people's behaviours as well as act as a catalyst for the development of business performance drivers, such as satisfaction, enthusiasm, flexibility, loyalty, creativity, change and innovation propensity, identity, diversity, culture, risk taking, and so on (Flam, 1993; Schiuma, 2009, 2011). They help to explain the organisation's capacity of being adaptable, resilient and innovative.

In the new digital age where the computational power of machines will enable higher efficiency and control, emotions play an important role in explaining the level of people's engagement which in turns affect the employees' capacity of being creative and innovative. This means that the digitisation process of organisations and economy will be coupled by an increasing acknowledgement that emotions and other soft dimensions such people's energy, experiences and ethics represent an important source for organisational performance. 
In order to enable people to discover and express their creative potentials and being engaged organisations can shape their organisational context into a creative environment. A creative environment aims 'to shape a space and time' in which people can be engaged with their emotions, exert creative thinking and deploy their energy in order to make an impact on organisational value creation dynamics. The creation of an organisational creative environment is based on the idea that technology and humanity can be synergistically integrated. It represents a platform in which the rational and emotive elements of an organisation are fused and nurtured by each other although they have a very different role. The emotive dimension involves touching people's feelings and moods, and making sure they are in touch with and present to themselves. Conversely, the rational dimension refers to the technologies, rational knowledge, and set of rules and procedures that define how activities have to be carried out.

The fundamental scope of a creative environment is to spur the full engagement of human potential and most importantly to avoid 'silos thinking', such as overspecialisation, and/or a paralysis of critical and creative thinking among employees. At the basis of the creation of a creative environment resides the recognition that organisations have a living nature and that at the heart of their value creation mechanisms there are people.

On the basis of the above assumptions in the next session it is discussed how organisations can shape creative environments by managing their aesthetic dimensions.

\section{Shaping creative environments by managing organisational aesthetic dimensions}

In shaping a creative environment, the key challenge for managers is how to practically handle the emotive characteristics and elements of an organisation so that they can be integrated with technology and the other technical and rational-based knowledge characterising of the organisation's processes. For this purpose, acknowledging the technohuman nature of an organisation, a powerful approach the management of the aesthetic characteristics of an organisation. Indeed, the organisational capacity of handling emotions and other key soft human-based value drivers, such as experiences, energy, engagement and ethics, can be built by focusing and managing the organisational aesthetic dimensions. In fact, aesthetics and emotions are two dimensions which are closely intertwined. Aesthetics generate feelings and feelings affect aesthetics. Aesthetics can be used to mobilise and manage emotions within and around organisations, and emotions can be put in place to better tune organisational aesthetic characteristics. The management of aesthetic dimensions within organisations equals to affect how people make sense of their outer and inner reality by using their senses. The management actions can be focused on the aesthetic experiences and/or properties of an organisation. Organisational aesthetic experiences refer to the quality of employees' experiences within the organisation, including their well-being, the quality of their daily work activities and the engagement level in what they do. This idea can be further extended to include all possible organisations' stakeholders; in which case the management of organisational experience corresponds to how stakeholders perceive the organisation and its products/services and activities. On the other hand, organisational aesthetic properties characterise the aesthetic qualities of the organisation as a whole. This involves the capacity of the organisation's tangible and intangible infrastructure (from equipment and workplace to culture and climate) to affect people's (stakeholders') experiences. For this reason, organisations are 
increasingly paying attention to the integration of interior design and playfulness in workplaces and are paying great attention to the creation of an organisational atmosphere in which employees could be happy, inspired and energised. However, the recognition of the role and relevance of the aesthetic dimensions of an organisation requires the definition of approaches and tools to handle the creation, development, and impact of the organisational aesthetic experiences and properties. For this reason, the knowledge domain of the arts can be approached and instrumentally used. In fact, the power of the arts is the capacity to define and shape aesthetic properties and experiences. Accordingly, the arts from an instrumental point of view can be considered as aesthetic technologies, i.e. art forms and/or artistry that are instrumentally used in order to deal with or solve a business/organisational issue. This means that from a practical point of view in order to manage organisational aesthetic dimensions artistic projects and practices can be adopted by organisations. Through the arts it is possible to foster people's aesthetic experiences and manipulate the aesthetic properties of an organisation's infrastructure. This, in turn, supports managers in handling the organisation's emotive, energetic, ethical, and experiential features and to integrate these dimensions with the organisations' rational-based assets and technology grounding the working mechanisms of business processes.

\section{Arts as a catalyst for the development of organisational creative environments}

The value of the arts has been explored from different point of view and it is a subject of debate, particularly, in the public discourse when to assess the investments for the arts and the cultural and creative sector. Indeed, the arts have a value of twofold nature. On the one hand, they have an intrinsic value which justifies the arts for the sake of arts because their role for expressing and defining humanity. On the other hand, the arts have a utilitarian value in which case their value is defined by the specific use of the arts in relation to some specific purposes. Both perspectives are important when analysing the role of the arts as a management means of the aesthetics characteristics of XXI century organisations (Schiuma, 2011). However, the utilitarian point of view explains the instrumental use of the arts as a vehicle that can inspire managers to develop management innovation, frame new organisational and business models, and draw on new approaches and instruments to tackle continuously emergent business challenges (Schiuma, 2011). In other words, the arts represent a knowledge domain which can be used to transform organisations and make them more suited to cope with the business challenges of the digital age (Adler, 2006; Austin and Devin, 2003; Darsø, 2004; Nissley, 2010; Schiuma, 2009; Taylor and Ladkin, 2009).

The arts have the power of influencing and creating organisational aesthetic properties and experiences (Strati, 2000a, 2000b). They can be adopted as an instrument to develop people and/or to change the organisation's infrastructure both tangibly and intangibly. Addressing people development issues, the arts can be deployed as a means to create aesthetic experiences that can affect employees' emotive, experiential, energetic and ethical dimensions with an impact on their level of engagement to the organisation's activities and life. On the other hand, the arts can be used as a tool for developing the organisation's infrastructure. They can be applied with the scope of affecting the aesthetic properties of the tangible and/or intangible components of an organisation. So, the arts can be deployed for designing and enriching workplaces, for 
communicating culture, identity and image of the organisation, for emotional-driven design of facilities, equipments and products, and for creating impactful meaning that can influence individual and collective behaviours as well as acting as drivers for personal development.

From a practical and operational standpoint, the managerial implementation of the arts is carried out by means of Arts-based Initiatives (ABIs) (Schiuma, 2009, 2011). An ABI is the planned managerial use of any art form or combination of art forms to address management challenges and business problems with the aim of developing employees and organisational infrastructure that positively affect the company's value creation capacity. The underlying assumption is that the adoption of ABIs is fundamentally aimed at humanising organisations, by harnessing the emotional and experiential dynamics characterising organisational life and business activities.

The ABIs stand for approaches and tools that instrumentally use the arts aim to create or to affect organisation's aesthetic dimensions. In this view, ABIs can be used specifically adopted as instruments to shape creative environments that acting as catalysers and amplifiers of human emotive abilities can foster the development of organisation's adaptability and continuous innovation. By adopting ABIs, organisations can employ and exploit the aesthetic properties and experiences associated to an artistic product and/or to an artistic process in order to create a frame of references which promote the connection of employees' technical and emotive knowledge.

Therefore, the deployment of the arts can enable organisations to shape a creative environment which can spark and support the integration and conversation between emotive and rational dimensions of an organisation.

In shaping creative environments, the arts can fundamentally play a twofold role. On one hand, they can act as a learning platform (Darsø, 2004). On the other hand, they can represent a device or vector to influence organisational aesthetic dimensions (Schiuma, 2009). The perspective recognising ABIs as a learning platform considers the arts as an instrument to support individual and organisational learning mechanisms both by transferring artistic skills, which are useful in the business context, and/or by shaping an experiential organisational atmosphere which can engage people with their emotions. The use of the arts as a learning platform is fundamentally aimed at developing human capital. This transformation is mainly based on the learning processes taking place both at the individual and at group level that nurture the development of employees. It may also have a positive impact on the internal and external organisational relationship dynamics as well as on the development of organisational and business models valuing emergent coordination, distributed wisdom, full engagement of people and distributed authority. In particular, arts-based methods are particularly useful to spark reflections on the leadership style and culture characterising an organisation. ABIs can be applied to develop and enhance leadership skills not only at top management level but across the entire organisation. This is particularly useful in those contexts in which there is a need for distributed leadership. Using arts-based methods employees can understand the meaning and the characteristics of leading and how to share this task with others. For example, using theatre applied methods people can be fostered to reflect on their values, on how they interact with others, on the challenges of directing a group and sharing the responsibilities and the trust among the group's members. 
The use of the arts as a device and vector is mainly related to the use of ABIs to embed aesthetic properties into tangible and intangible organisational infrastructure and products. So, for example, the arts can be used as a way to shape workplaces that can be inspiring. Offices can be artistically designed and beautified in order to spark and energise people. But the use of the arts can be also focused on managing the intangible elements of the organisational capital such as, for example, culture, values, identity and image. These dimensions can be made visible, more understandable and emotive through the use of artworks that symbolise them. For instance, the use of sculptures or visual arts can be deployed to represent metaphorically the identity of the company and its fundamental values.

The adoption of the arts either as a learning platform or as a device, allows shaping creative environments; by creating a frame of references in which rational organisational characteristics that are ingrained in the working mechanisms of today's organisations are put in conversation and integrated with the emotive features.

In the next section the case example of Elica, a world leading Italian company in the production of kitchen hoods, is presented. Elica despite being an advanced technologybased organisations, is systematically using the arts as a managerial instrument to support the development of the organisation as a human-centred living organism as well as a means to foster creative processes and maintain an organisational creative environment.

The case of Elica: Insights on the use of arts to shape a creative environment

Elica is world leader technology company specialised in the design, production and commercialisation of kitchen hoods and also design, manufacture and sell motors for central heating boilers for domestic use. It has a market share of $17 \%$ in the world and 43\% in Europe. With over 2,300 employees and an annual output of about 16 million units of kitchen hoods and motors, the Elica Group has ten plants: five are in Italy, one is in Poland, one in Mexico, one in Germany, one in India and one in China.

The fundamental competitive value drivers of Elica's products are: the integration of high technological quality with a design driven innovation capability, and the aesthetical dimensions combined with high functional quality.

Elica has achieved a world leading competitive position by revolutionising the traditional mature sector of the kitchen hoods. In particular, the company has changed the traditional image of the kitchen cooker hood transforming it from a simple accessory and household appliance into a design object. Elica's products are associated with an image of unique objects, with unusual shapes and incorporating innovative technologies. They combine meticulous care for the design, for the quality of material and for cutting edge technology, which is also the result of the partnerships created with world leading technology-based companies such as Artemide, in the lighting sector, and Whirlpool, in green and smart technologies.

The fundamental idea behind Elica's products is that they have to represent sources of inspiration and wellbeing, beautiful to look at and capable of providing the highest technological performance in order to meet customers' wants and needs. In other words, they are interpreted as an important component of the living house. In this perspective Elica's products are designed and produced on the basis of high technological and aesthetic features making sure they embed intangible value and generate positive experiences for customers. In order to meet this challenge, Elica has understood that 
the development of products that can have a positive impact on people, first and foremost is driven by an organisation which deeply embeds the features and potential of human nature. Consequently, they have developed a strong awareness about the relevance of being and operating as a human-centred living organism, paying great attention to managing organisational aesthetic dimensions and handling emotive features.

Elica attributes a fundamental centrality to people whose technical and emotive competences are considered the engine of competitive success. As stated by the Deborah Carè, Elica Group Brand Marketing Manager, the notion of promoting creativity is fundamentally interpreted by the organisation as the capacity of coping with the risk of the 'paralysis of thinking'. For Elica, it is essential that employees do not carry out their activities in a mechanistic way without too much questioning about it. Elica strongly believes that it is fundamental to foster the development of a creative environment which encourages people to think and to engage in what they do. This is considered essential in order to foster an organisational environment capable ultimately of developing and producing products that combine and embed high technology and emotive/ aesthetical features. For this reason, they have integrated in the management system the use of the arts as a managerial instrument to support the development of employees' adaptability to changes and their innovation-oriented behaviour.

Elica interprets the arts as a powerful means to push the organisation beyond the traditional business model and break conventional paradigms that have characterised the company in the past when it was just focused on producing standard appliance hoods.

Elica is using the arts as a strategic managerial instrument to nurture an organisation's behaviour towards imagination, innovation behaviour, problem solving oriented capability, and creativity. Some of the main organisational issues addressed through the arts are: communication of the company's philosophy, development of productive and wellbeing-oriented workplaces, strengthening of ties with clients and more generally with society and territory, employees' development, promotion and communication of organisational image and reputation, enhancement of product development capacity.

From an operational point of view, Elica has launched different ABIs to shape a creative environment. In particular, identifying people and workplaces as two fundamental dimensions of the creative environment they have developed two specific artsbased programs as follows: the program named "Lifestyle" and the program named "E-straordinario".

The Elica's program "Lifestyle" aims to shape workplaces that secure wellbeing and productivity as well as create an atmosphere which spurs creativity and positive emotions so that new ideas can converge and be created. According to Elica the workplaces have to be a kind of 'open porthole' on a different concept of being, of living and acting; so they have to be places for meeting and renovating the mind. The creation of engaging workplaces is achieved by adopting the arts as an instrument to shape the aesthetic properties of facilities and organisation's culture, values, identity and more generally climate. Offices are artistically designed and host exhibitions both of artworks from public and private contemporary art collections, and of artistic artefacts created by employees with the support and facilitation of artists. Among the different Lifestyle's initiatives, it is worth mentioning Elica Contemporary which has is based on the idea that artworks together with the company's products are exhibited in different spaces within the company. This has an impact on the aesthetic characteristics of the 
workplace, on the capacity of communicating the company's identity highlighting its mission of creating products which aspire to be 'artworks for the living house', and on the engagement level of employees fostering their pride in the results of their work activities.

On the other hand, the program E-straordinario is aimed at supporting employees' development. Its purpose is the creation of an aesthetic experiential learning process that can engage employees with their emotions. It works on the basis of a set of conceptual and practical arts-based seminars and workshops in which artists work on a project within the organisation and with employees. The selected artists brought into the company are asked to conceive and carry out an artwork which can engage the company's employees intellectually, emotionally and physically. The artist(s) works with a facilitator in order to make sure that the insights can be distilled from the arts-based initiatives. The artists' projects to be implemented in the organisation are selected on the basis of different criteria, particularly: experimentation, contamination of different codes, hands-on participation of employees, quality of contents, capacity of challenging established habits and behaviours, moving employees out of their comfort zone, and the use of the arts as an ethical model.

Both programs are based on the fundamental assumption that people have a central role in organisational value creation capacity and competitiveness. They are aimed at creating space and time fostering the integration of the organisation's emotive and rational dimensions. By affecting people's aesthetic experiences, the arts stimulate human senses and create processes or contexts in which people's emotions arise and can be combined with rational elements grounded in the organisation's working activities. By blending the emotive reality with the traditional rational working mechanisms, Elica has been able to shape a creative environment which is producing positive impact on people's innovation behaviours and more generally on company innovation capacity.

Although the case example of Elica cannot be generalised, it offers important insights and implications to identify some critical factors about the relevance of the arts for shaping a creative environment in the new Digital Age.

\section{Conclusion}

Today's digital era challenges organisations not only to follow the technological trajectories, by developing new technological solutions and/or adopting the latest disruptive technology, but most importantly to become creative and resilient organic systems that are open to changes and keen to experiment and innovate continuously. The view of the organisation as a techno-human system points out that organisations need to integrate the traditional rational-based principles and technology assets with the emotive features of human life and understand that emotions play a fundamental role in the organisational life and in the pursuit of business excellence.

Emotions denote all those factors of human expression that cannot be reduced to rules/procedures or technological components; rather they need to be disclosed and channelled for contributing to the organisational value creation mechanisms. On the other hand, technology guarantees efficiency and control. Both rationality and emotions, technology and humanity, matter for the success of an organisation and in the new Digital Age they need to be integrated. For this reason, organisations need to 
shape a creative environment in which technology and creativity are fused and intertwined.

In order to shape a creative environment, it is suggested that organisations manage their aesthetic dimensions. For this purpose, the use of the arts is proposed as a management instrument to shape the organisation's aesthetic experiences and properties which in turn can support handling emotive elements in organisational contexts. From a practical point of view the arts can be deployed within organisations to shape creative environments in the form of Arts-based Initiatives (ABIs).

In conclusion, the successful organisations of the Digital Age will be those recognising that as much as they will become more technologically advanced, the people will still be at the heart of organisational life and actually the most human distinguishing factors will become even more fundamental for the creation and deliver of value. The use of the arts is aimed at making organisations more human, acknowledging the human-based nature of organisations and business, and their role to make organisations intuitive, imaginative, creative and resilient. A creative environment is capable of engaging employees in their daily work activities, of inspiring executives to build igniting visions and energise people, and of making organisations more aware of the value propositions delivered to stakeholders. As pointed out by Steve Jobs "Technology alone is not enough - it's technology married with liberal arts, married with the humanities, that yields us the result that makes our heart sing".

\section{Note}

I confirm that I have read SpringerOpen's guidance on competing interests and I have any competing interests in the manuscript.

\section{Acknowledgements}

I would like to thank the DGIST Convergence Research Center for Future Automotive Technology, for their award to support the publication of this article as open access material.

Funding

Not applicable.

Availability of data and materials

Data and information have been collected by the author.

Authors' contributions

All paper

Authors' information

Dr Giovanni Schiuma is Professor of Innovation Management at University of Basilicata (Italy) and Visiting Professor of Arts Based Management at University of the Arts London, where he founded and developed as Director the Innovation Insights Hub. Giovanni is widely recognized as one of the world's leading experts in strategic knowledge management, business model innovation of arts and cultural organisations, company's value creation dynamics and the arts in business for organisational development and innovation. Giovanni holds a Ph.D. in business management from the University of Rome Tor Vergata (Italy) and has authored or co-authored more than 200 publications, including books, articles, research reports and white papers.

Competing interests

The authors declare that they have no competing interests.

\section{Publisher's Note}

Springer Nature remains neutral with regard to jurisdictional claims in published maps and institutional affiliations. 
Received: 14 September 2017 Accepted: 13 October 2017

Published online: 23 October 2017

\section{References}

Adler, N. J. (2006). The Arts \& Leadership: Now that we can do anything, what will we do? Academy of Management Learning \& Education, 5, 486-499.

Adler, N. J. (2010). Going beyond the dehydrated language of management: leadership insight. Journal of Business Strategy, 31(4), 90-99.

Austin R., and Devin L., Artful Making: What Managers Need to Know About How Artists Work, (New York: Prentice-Hall, 2003) Burns T. and Stalker G.M., The Management of Innovation (London: Tavistock, 1961)

Darsø, L. (2004). Artful Creation - Learning-tales of Arts-in-business. Gylling: Narayana Press.

Evans and Annunziata (2012), Industrial Internet: Pushing the boundaries of minds and machines, GE Imagination at work, GE Report. Fineman S., Social Work Stress and Intervention (Gower: Brookfield, 1985)

Flam, H. (1993). Fear, Loyalty and Greedy Organisations. In S. Fineman (Ed.), Emotion in Organisations (pp. 58-75). London: Sage.

Frank R.H., Passions within Reason: The Strategic Role of the Emotions (New York: W.W. Norton, 1988)

Frost, P. J., Moore, L. F., Louis, M. R., Lundberg, C. C., \& Martin, J. (1985). Organisational Culture. London: Sage.

Hamel G., Leading the revolution (Boston: Harvard Business School Press, 2000)

Hamel G., The Future of Management (Boston: Harvard Business School Press, 2007)

Hamel, G. (2009). Moon Shots for Management. Harvard Business Review, 87, 91-98.

Linstead S., and Höpfl H. (ed.), The Aesthetics of Organisation (London: Sage Publications, 2000)

Mintzberg, H. (1985). The organisation as a political arena. Journal of Management Studies, 22, 133-154.

Nissley, N. (2010). Arts-based learning at work: economic downturns, innovation upturns, and the eminent practicality of arts in business. Journal of Business Strategy, 31(4), 8-20.

Richards, D. (1995). Artful work: Awakening joy, meaning, and commitment in the workplace. San Francisco: BerrettKoehler.

Schiuma G., (2009), "Mapping Arts-Based Initiatives - Assessing the Organisational Value of Arts", Arts\&Business, UK.

Schiuma G., The Value of Arts for Business, (Cambridge: Cambridge University Press, 2011)

Klaus Schwab (2016), The Fourth Industrial Revolution, World Economic Forum, New York.

Strati, A. (1992). Aesthetic Understanding of Organisational Life. Academy of Management Review, 17, 568-581.

Strati A., 'Aesthetic Theory', in Linstead H. and Hopfl H. (eds.), The Aesthetics of Organisation (London: Sage Publications, 2000a)

Strati A., Theory and Method in Organisation Studies (London: Sage Publication, 2000b)

Taylor, S. S., \& Hansen, H. (2005). Finding form: looking at the field of organizational aesthetics. Journal of Management Studies, 42(6), 1211-1231.

Taylor, S. S., \& Ladkin, D. (2009). Understanding Arts-Based Methods in Managerial Development. Academy of Management Learning \& Education, 8, 55-69.

Turner, B. (1990). Organisational Symbolism. Berlin: De Gruyter.

\section{Submit your manuscript to a SpringerOpen ${ }^{\circ}$ journal and benefit from:}

- Convenient online submission

- Rigorous peer review

- Open access: articles freely available online

- High visibility within the field

- Retaining the copyright to your article

Submit your next manuscript at $\gg$ springeropen.com 